\title{
Religious Affections Jonathan Edwards dan Relevansinya bagi Ibadah Komunal
}

\author{
Lucky Samuel* \\ *Penulis adalah rohaniwan bidang Ibadah di GKY Jemaat Mangga Besar, Jakarta. Ia memperoleh gelar Mas- \\ ter of Theology in Worship dari Calvin Theological Seminary (USA), setelah sebelumnya memperoleh gelar \\ Sarjana Teologi dari Seminari Alkitab Asia Tenggara (Malang), dan Master of Ministry dari Trinity Theologi- \\ cal College (Singapore). \\ Email: lucharista@gmail.com
}

\begin{abstract}
Abstrak: Artikel ini mencoba untuk membahas kontribusi dari salah satu tulisan penting Jonathan Edwards, yaitu A Treatise Concerning Religious Affections, bagi ibadah komunal. Sebagaimana karya ini bermanfaat dalam mengevaluasi kerohanian seseorang dan merumuskan apa itu spiritualitas yang autentik, risalah ini juga dapat bermanfaat di dalam mengevaluasi dan merancang ibadah komunal. Berfokus pada tiga tanda pertama dari dua belas indikator spiritualitas yang sejati menurut Edwards, tulisan ini mengusulkan bahwa risalah ini dapat berfungsi sebagai penawar dari tiga pemahaman menyimpang dalam ibadah komunal: ibadah yang legalistik, narsisistik, dan terapeutik.
\end{abstract}

Kata-kata kunci: Jonathan Edwards, Afeksi Religius, Ibadah Komunal, Spiritualitas

Abstract: This article attempts to discuss one of the important writings of Jonathan Edwards, A Treatise Concerning Religious Affections, and its contribution to corporate worship. Since this work has been helpful in evaluating one's spirituality and in formulating what the authentic spirituality is, this treatise can be also useful in evaluating and designing corporate worship. Focusing on the first three signs of gracious affections according to Edwards, this paper suggests that this treatise can serve as an antidote for three distorted notions in corporate worship, namely legalistic, narcissistic, and therapeutic worship.

Keywords: Jonathan Edwards, Religious Affections, Corporate Worship, Spirituality 


\section{Pendahuluan}

Religious Affections ${ }^{1}$ (selanjutnya disingkat: $R A$ ) adalah salah satu karya yang paling berpengaruh yang pernah ditulis oleh Jonathan Edwards (1703-1758). Tidaklah berlebihan jika, mengutip Nichols, tulisan ini disebut sebagai "sejenis buku yang melampaui generasinya sendiri ... sebab buku ini membahas sejumlah problem yang, dari generasi ke generasi, menjadi wabah bagi orang Kristen dan gereja." 2 Di dalam buku ini, Edwards memaparkan keyakinannya bahwa "agama yang sejati, bagian terbesarnya, diisi oleh afeksi-afeksi yang kudus."3 Kemudian, dia mengembangkan ide tersebut dengan memberikan dua belas tindakan yang tidak bisa menjadi jaminan dari keautentikan spiritualitas seseorang. Lalu di bagian yang terakhir dari bukunya, Edwards menawarkan dua belas tanda yang dapat berfungsi sebagai indikator spiritualitas yang asli. ${ }^{4}$ Pendekatan yang ditawarkan Edwards dapat menjadi salah satu sumber yang bermanfaat untuk membangun kehidupan rohani yang sejati. Kegunaannya dapat dilihat setidaknya dalam dua hal: pertama, dalam mengevaluasi ide dan praktik seseorang tentang spiritualitas, dan kedua, dalam membangun kehidupan spiritualitas yang sejati.

Jika konsep yang dipaparkan Edwards dalam $R A$ sedemikian penting dan bermanfaat dalam kehidupan spiritualitas secara personal, apakah konsep yang sama juga bisa berguna bagi area spiritualitas yang komunal, khususnya

\footnotetext{
${ }^{1}$ Jonathan Edwards, Religious Affections, vol. 2 dalam The Works of Jonathan Edwards, ed. John E. Smith, (New Haven: Yale University Press, 1959). Seluruh kutipan dari $R A$ di dalam tulisan ini merujuk pada edisi ini, dan diterjemahkan ke dalam bahasa Indonesia oleh penulis, dengan mempertahankan susunan kalimat aslinya. Pembaca yang ingin membaca karya aslinya bisa mengakses secara gratis di situs Jonathan Edwards Center di Yale University, di http://edwards.yale.edu.
}

${ }^{2}$ Stephen J. Nichols, Jonathan Edwards: A Guided Tour of His Life and Thought (Phillipsburg: P\&R, 2001), 107.

${ }^{3}$ Edwards, Religious Affections, 95.

${ }^{4}$ Untuk intisari $R A$ yang telah disederhanakan dan diterjemahkan ke dalam bahasa Indonesia, lih. Jonathan Edwards, Pengalaman Rohani Sejati (Surabaya: Momentum, 2003). ibadah Minggu? Pertanyaan ini patut untuk direnungkan sebab, sebagaimana yang dikemukakan oleh Dyrness, model-model ibadah komunal sejatinya adalah model-model spiritualitas. $^{5}$ Baginya, kebiasaan-kebiasaan (habits) yang dipraktikkan dalam ibadah komunal sesungguhnya berdampak jauh menembus tembok gereja. Bahkan bagi sebagian besar orang Kristen, tindakan tertentu dalam ibadah, misalnya membuat tanda salib (sign of the cross) tiap kali berdoa, dipahami sebagai ciri yang tidak boleh tidak ada jika seseorang ingin disebut Kristen; yang namanya orang Kristen ya ketika berdoa membuat tanda salib.

Topik tentang Edwards dan ibadah komunal, sebagaimana yang dicermati oleh Rivera, "masih menjadi isu yang hampir-hampir tidak tersentuh di dalam dunia kesarjanaan Edwards, dan Edwards sendiri memang tidak pernah menulis sebuah risalah yang lengkap tentang topik ini." ${ }^{\circ}$ Namun, sebagaimana yang diyakini oleh Rivera di dalam bukunya tentang Edwards dan ibadah, "Jonathan Edwards, dengan kebajikannya yang bergantung penuh kepada Alkitab dan wawasannya yang unik, menawarkan nasihat yang bermanfaat sehubungan dengan ibadah Kristen hari ini." ${ }^{\prime}$ Namun menariknya, meski Rivera menaruh fokusnya pada karya-karya Edwards sebagai sumber pembahasannya tentang iba-

${ }^{5}$ Lih. William Dyrness, A Primer of Christian Worship: Where We've Been, Where We Are, Where We Can Go (Grand Rapids: Eerdmans, 2009), 50-52.

${ }^{6}$ Ted Rivera, Jonathan Edwards on Worship: Public and Private Devotion to God (Eugene: Pickwick Publications, 2010), 1.

${ }^{7}$ Ibid., 2. Di dalam pendahuluan buku Rivera, Ken P. Minkema, salah satu sarjana Edwards yang ternama dari Yale, menuliskan kalimat ini: "Studi dari Ted Rivera adalah upaya sistematis yang pertama untuk menunjukkan pandangan-pandangan Edwards tentang ibadah dan oleh sebab itu, merupakan sebuah sumber yang penting bagi para sarjana dan praktisi keagamaan di bidang yang sama, yang memiliki ketertarikan di bidang liturgi" (lih. ibid., ix). Menurut hemat penulis, pernyataan Minkema penting setidaknya dalam dua hal: pertama, bahwa Edwards memang memiliki sesuatu untuk disampaikan di bidang ibadah baik secara komunal maupun personal, dan; kedua, bahwa akan ada lebih banyak diskusi-diskusi di masa depan mengenai topik ini. 
dah, ia secara sengaja tidak memasukkan $R A$ sebagai salah satu sumber diskusinya. ${ }^{8}$

Upaya lain untuk menggali kontribusi karya Edwards di dalam area ibadah komunal juga dilakukan oleh Kendra G. Hotz dan Matthew T. Mathews-dua orang profesor dari Memphis Theological Seminary, di Tennessee, Amerika Serikat. ${ }^{9}$ Berbeda dengan Rivera, karya Hotz dan Mathews secara khusus membahas korelasi antara religious affections dan ibadah korporat. Secara spesifik, mereka mencoba mengeksplorasi bagaimana elemenelemen di dalam ibadah Minggu dapat membangkitkan religious affections dari jemaat yang menghadirinya. Namun, tidak kalah menariknya, meski mereka secara terangterangan menyatakan diri berhutang ide kepada Edwards, ${ }^{10}$ buku ini pada dasarnya tidak mendiskusikan $R A$ secara ekstensif.

Artikel ini merupakan sebuah upaya kecil untuk mendiskusikan celah yang ditinggalkan oleh karya-karya sebelumnya, yaitu untuk menggali kontribusi Edwards di dalam area ibadah komunal, yang secara khusus difokuskan melalui kacamata karyanya yang penting, yaitu $R A$. Meski tulisan ini utamanya akan membahas $R A$, penulis juga akan berinteraksi dengan berbagai sumber yang berhubungan dengan $R A$, serta dengan tulisan-tulisan seputar studi ibadah. Argumen utama dari tulisan ini adalah bahwa $R A$ bukan hanya dapat memberikan masukan yang berharga ketika kita memikirkan ibadah komunal, tetapi $R A$ juga bisa berfungsi sebagai sebuah penawar bagi tiga "penyakit" umum yang telah mewabah dalam ibadah komunal: ibadah yang legalistik, narsisistik, dan terapeutik.

Perlu ditegaskan bahwa, sebagaimana yang akan dibahas nanti, $R A$ bukanlah risalah tentang ibadah, apalagi ditujukan untuk menjawab berbagai polemik dan isu di dalam ibadah hari ini. Apa yang ingin penulis paparkan

\section{${ }^{8}$ Lih. ibid., 6.}

${ }^{9}$ Kendra G. Hotz dan Matthew T. Mathews, Shaping the Christian Life: Worship and the Religious Affections (Louisville: Westminster John Knox, 2006).

${ }^{10}$ Lih. ibid. xi. di dalam tulisan ini adalah bagaimana hikmat yang terkandung dalam $R A$ dapat menolong kita untuk mengevaluasi dan merancang ibadah. Membaca $R A$ sembari memikirkan ibadah komunal akan membantu kita untuk melihat bahwa sebagaimana kita perlu terus mengevaluasi spiritualitas kita, demikian pula dengan ibadah komunal kita. Kejelian Edwards dalam melihat problematika seputar spiritualitas yang autentik tentu akan sangat bermanfaat juga untuk merumuskan unsurunsur apa saja yang menjadikan sebuah ibadah itu autentik. Selain itu, artikulasi Edwards yang jelas dan kokoh tentang apa itu kerohanian sejati dapat menolong kita untuk mendefinisikan ulang pemahaman dan keyakinan kita tentang ibadah yang sejati.

Sebelum melihat hikmat yang bisa digali dari $R A$ terkait dengan ibadah komunal, pertamatama, penting bagi kita untuk melihat sekilas latar belakangnya. Pada bagian ini, kita juga akan secara singkat mendiskusikan bagaimana konteks Edwards, di dalam beberapa hal, relevan dengan situasi hari ini. Selanjutnya, oleh karena keterbatasan ruang pembahasan, kita hanya akan berfokus pada bagian terakhir dari $R A$, secara khusus pada tiga tanda pertama dari dua belas indikator spiritualitas yang sejati. Alasan lain untuk membatasi diskusi artikel ini hanya pada tiga tanda tersebut adalah karena, di dalam istilah Edwards sendiri, tiga tanda tersebut mendiskusikan sumber dan dasar dari tanda-tanda lainnya di dalam bagian ini. Di akhir dari tulisan ini, penulis akan menawarkan beberapa ide praktis untuk mengaplikasikan masukan-masukan bernilai dari $R A$ ke dalam ibadah komunal.

\section{Religious Affections dan Ibadah Komunal Hari Ini}

Salah satu topik yang hangat didiskusikan oleh gereja di beberapa dekade belakangan ini adalah tentang ibadah komunal. Ada cukup banyak buku bertemakan ibadahkhususnya yang berbahasa Inggris-yang telah ditulis oleh ahli liturgi, teolog, pendeta, 
termasuk praktisi ibadah. ${ }^{11}$ Belum lagi ditambah dengan berbagai konferensi dan simposium bertajuk ibadah, baik yang diselenggarakan secara sporadis di gereja-gereja lokal, hingga yang bersifat sinodal bahkan berskala nasional. Tidaklah berlebihan jika kita menyimpulkan bahwa ibadah, khususnya ibadah komunal, merupakan salah satu isu yang signifikan bagi kekristenan dewasa ini.

Sayangnya, selain menjadi tema yang hangat dibicarakan, ibadah juga menjadi salah satu isu yang sering diperdebatkan. Salah satu persoalan krusial yang diperdebatkan di dalam diskusi-diskusi tentang ibadah adalah berkenaan dengan pertanyaan ini: "Bagaimana ibadah komunal bisa tetap setia kepada firman Tuhan, dan di saat yang sama, relevan bagi budaya hari ini?" Tidaklah mudah untuk menjawab pertanyaan di atas. Faktanya, upaya-upaya untuk menjawab pertanyaan tersebut telah memicu ketegangan, baik di antara anggota sesama gereja, maupun di antara satu gereja dengan yang lainnya. Ketegangan inilah yang sering kali dikenal dengan istilah "perang-perang ibadah" atau "worship

${ }^{11}$ Salah satu rujukan yang bermanfaat untuk melihat daftar buku-buku tentang ibadah bisa dilihat di situs The Robert Webber Institute for Worship Studies, "IWS Bibliography January 2015," diakses 4 Januari 2016. https:// iws.edu/2014/12/iws-bibliography-jan-2015/. Sayangnya, di antara sekian banyak tulisan tentang ibadah, hanya sedikit sekali yang berbahasa Indonesia, baik yang dikarang oleh orang Indonesia, maupun yang diterjemahkan ke dalam bahasa Indonesia. Implikasinya tentu sangat signifikan. Pertama, bukan saja orang Kristen di Indonesia kurang mendapat wawasan yang mudah diakses tentang ibadah komunal, tetapi yang lebih utama, juga para mahasiswa teologi, rohaniwan, dan praktisi ibadah, yang seharihari bergulat dengan aktivitas seperti merancang ibadah, memimpin ibadah, memberikan pelatihan atau pembinaan ibadah. Maka tidak heran jika pembicaraan seputar ibadah sering kali cenderung destruktif-mengarah pada perpecahan, daripada konstruktif-mengarah pada praktik ibadah yang alkitabiah. Implikasi kedua, yang tidak kalah penting, adalah terbatasnya sumber-sumber dari negara Barat untuk diaplikasikan secara kontekstual di Indonesia. Akibatnya, alih-alih menemukan dan mengembangkan ibadah yang dekat dengan budaya lokal, elemen-elemen ibadah komunal di kebanyakan gereja sering kali merupakan hasil impor yang sarat dengan budaya di mana sumber tersebut berasal. Singkatnya, dibutuhkan lebih banyak lagi tulisan-tulisan bertemakan ibadah di dalam bahasa Indonesia. wars." 12 Realitas ini menunjukkan bahwa ibadah bukan hanya isu yang penting, tetapi juga sulit untuk diperbincangkan.

Jika "perang-perang ibadah" merupakan problem di banyak gereja hari ini, isu besar yang paling santer di zaman Edwards adalah perdebatan mengenai kebangunan rohani (awakening). ${ }^{13}$ Kelompok yang sangat antusias dengan kebangunan rohani-diwakili oleh James Davenport (1716-1757)—mengampanyekan perlunya pengalaman tertentu yang sifatnya sensasional, fisikal, dan emosional di dalam gereja, sebagai bukti dari spiritualitas yang sejati. ${ }^{14}$ Sebaliknya, kelompok yang mati-matian menentang kebangunan rohani-dipimpin oleh Charles Chauncy (1705-1787)—menuduh lawan mereka bahwa

\footnotetext{
${ }^{12}$ Untuk pembahasan lebih mendalam mengenai topik ini, lih. Elmer L. Towns, Putting an End to Worship Wars (Nashville: Broadman \& Holman, 1997), 9-61; Ronald P. Byars, The Future of Protestant Worship: Beyond the Worship Wars (Louisville: Westminster John Knox, 2002), 8-20; Thomas G. Long, Beyond the Worship Wars (Bethesda: The Alban Institute, 2001), 1-14.
}

${ }^{13}$ Smith menuliskan: "Periode di zaman dia [Edwards] menulis didominasi oleh fenomena yang dikenal dengan revivalism, dan khususnya di masa yang oleh orang Amerika dikenal dengan Kebangunan Rohani Raya (the Great Awakening). Sesungguhnya ada beberapa seri kebangunan, beberapa besar, beberapa kecil, yang dimulai oleh Solomon Stoddard dengan lima "masa menuai" jiwa-jiwa di Northampton di antara tahun 1679 dan 1718, dan berlanjut semakin hangat di tahun 1734-35 hingga pada klimaksnya di tahun 1740 (Editor's Introduction to Religious Affections, oleh Jonathan Edwards, 3). Ulasan lebih lengkap mengenai latar belakang historis dari Kebangunan Rohani Raya dan bagaimana peristiwa tersebut memicu ditulisnya $R A$, lih. Robert Davis Smart, Jonathan Edwards's Apologetics for the Great Awakening (Grand Rapids: Reformation Heritage Books, 2011), 13-35; Sam Storms, Signs of the Spirit: An Interpretation to Jonathan Edwards' "Religious Affections" (Wheaton: Crossway, 2007), 21-35.

${ }^{14}$ Di dalam biografi Edwards yang ditulisnya, Marsden mencatat bahwa selama masa Kebangunan Rohani Raya yang dipicu oleh pelayanan George Whitefield (17401741), ada berapa fenomena tidak lazim yang muncul. Ketika fenomena tersebut dipopulerkan oleh pengkhotbah keliling seperti Davenport, Wheelock, Buell, dan Pomeroy, maka fenomena-fenomena tersebut "menjadi standar, bahkan diharapkan" (lih. Jonathan Edwards: A Life [New Haven: Yale University Press, 2003], 269. Pembahasan lebih lanjut mengenai Davenport, lih. juga ibid., 232-233; Craig Biehl, Reading Religious Affections: A Study Guide to Jonathan Edwards' Classic on the Nature of True Christianity (Birmingham: Solid Ground Christian Books, 2012), $14-16$. 
mereka sedang di bawah pengaruh "imajinasi yang kelewat panas" daripada dipimpin oleh roh Tuhan. ${ }^{15}$ Inti dari konflik dua kelompok ini adalah mengenai apakah perasaan religius (religious feeling) — sebagaimana yang dipertahankan oleh kelompok antusias-atau, pemikiran yang benar (right thinking) — seperti yang disuarakan oleh kelompok rasionalis-yang adalah jantung dari kerohanian yang sejati.

Tujuan utama Edwards menulis $R A$ adalah untuk menjawab polemik tersebut. Menurut McDermott, di dalam risalahnya, Edwards "berargumen bahwa dua kelompok tersebut telah berpikir dangkal mengenai spiritualitas."16 Dengan membaca bagian pertama dari $R A$ saja, kita dapat segera menangkap kehati-hatian Edwards di dalam menghadapi polarisasi antara hati dan akal, yaitu dengan memilih istilah lain yang dia sebut sebagai "afeksi." Bagi Edwards afeksi adalah sesuatu yang melampaui apa yang ditangkap oleh akal semata-mata, dan lebih dari sekadar apa yang dirasakan oleh emosi belaka. Afeksi adalah, sebagaimana yang dengan tepat dirangkumkan oleh Smart, "inklinasi terkuat dari hati yang dimanifestasikan di dalam pemikiran, perasaan, dan tindakan." 17 Di dalam definisi Edwards sendiri, afeksi adalah "tindakan-tindakan yang penuh kekuatan dan hidup dari inklinasi dan kehendak jiwa, atau aktivitas hati yang membara." 18

Setelah melihat ke dalam konteks Edwards, setidaknya ada dua aspek yang relevan dari $R A$ terhadap diskusi tentang ibadah komunal. Pertama, $R A$ ditulis untuk menjawab pertanyaan: "Apa itu kerohanian yang sejati?" Mengingat spiritualitas dan ibadah adalah dua hal yang berhubungan erat, $R A$ dapat

\footnotetext{
${ }^{15}$ Bacaan lebih lanjut tentang Chauncy dan kritiknya terhadap Edwards, lih. Smart, Jonathan Edwards's Apologetics, 161-241; Marsden, Jonathan Edwards: A Life, 268290; Conrad Cherry, The Theology of Jonathan Edwards: A Reappraisal (Indianapolis: Indiana University Press, 1990), 164-176.

${ }^{16}$ Gerald R. McDermott, Seeing God: Twelve Reliable Signs of True Spirituality (Downers Grove: InterVarsity Press, 1995) 31.
}

${ }^{17}$ Smart, Jonathan Edwards's Apologetics, 265.

${ }^{18}$ Edwards, Religious Affections, 99. membantu kita untuk menjawab pertanyaan serupa, yaitu: "Apa itu ibadah yang sejati?" Sebagai tambahan, Susan White menyatakan bahwa ibadah terkait erat dengan spiritualitas karena "asupan nutrisi utama bagi kehidupan rohani orang Kristen adalah di dalam ibadah komunal di gereja." 19 Akibatnya, apa pun yang kita lakukan di dalam ibadah komunal pasti berdampak pada kehidupan spiritual kita. Dengan cara yang sama, apa pun yang kita pikirkan tentang spiritualitas pasti berimplikasi kepada apa yang kita pikirkan tentang ibadah.

Kedua, $R A$ ditulis untuk memberikan pemahaman yang seimbang mengenai dikotomi antara hati dan pikiran, antara kelompok emosional dan rasional, di dalam hubungannya dengan spiritualitas yang autentik. Polemik ini juga merupakan salah satu hal yang menonjol di dalam perdebatan tentang ibadah, di mana ada ketidaksepahaman mengenai apakah ibadah merupakan waktu untuk ekspresi (hati) atau edukasi (pikiran). Sebagaimana yang penulis sebutkan di atas, konsep "afeksi" yang ditawarkan Edwards memberikan kita perspektif yang lebih komprehensif dan holistik, yang melampaui dikotomi tersebut. Cara Edwards menyoroti masalah ini akan bermanfaat juga di dalam area ibadah.

\section{Kontribusi Religious Affections bagi Ibadah Komunal}

Untuk menggali kontribusi Edwards bagi ibadah komunal melalui kacamata $R A$, kita harus memahami bahwa meski kata "ibadah (worship)" muncul beberapa kali, kita tidak akan menemukan ulasan yang spesifik mengenai ibadah komunal di dalam risalah ini, selain dari sebuah peringatan keras bahwa walaupun seseorang begitu aktif dalam berbagai aktivitas beribadah, itu tidaklah menjamin bahwa orang tersebut memiliki afeksi yang kudus. ${ }^{20}$ Namun, kita dapat meyakini bahwa ibadah komunal ada di dalam pikiran Edwards pada waktu dia menyatakan bahwa doa, pujian,

\footnotetext{
${ }^{19}$ Susan J. White, Spirit of Worship: The Liturgical Tradition (Maryknoll: Orbis, 1999), 15.

${ }^{20}$ Edwards, Religious Affections, 165.
} 
sakramen, dan khotbah-elemen-elemen dasar dalam ibadah Minggu-dirancang oleh Tuhan untuk membangkitkan afeksi religius kita. ${ }^{21}$ Di bagian ini, kita akan membahas tiga ide tentang afeksi yang sejati menurut Edwards, dan bagaimana tiga ide tersebut relevan terhadap diskusi kita tentang ibadah komunal.

\section{Religious Affections dan Ibadah yang Legalis- tik: Tanda 1}

Dari jumlah halamannya, tanda pertama dari afeksi yang penuh anugerah (gracious) adalah eksposisi yang terpanjang dibandingkan sebelas tanda lainnya. Di bagian ini ia menjelaskan bahwa, "Afeksi yang sungguhsungguh spiritual dan penuh anugerah, lahir di dalam hati dari pengaruh-pengaruh atau aktivitas-aktivitas yang sifatnya spiritual, supranatural, dan ilahi."22 Menurut Biehl, eksposisi panjang ini bisa dibagi ke dalam enam sub-bagian:23 (1) definisi apa itu spiritual; (2) perbedaan sumber dari afeksi yang spiritual dengan afeksi yang natural; (3) persamaan antara afeksi yang spiritual dan natural; (4) afeksi yang penuh anugerah dan kudus dapat dipalsukan; (5) natur dari impresi, imajinasi, dan penglihatan/visi, dan; (6) kesaksian dari Roh Kudus.

Jika ada yang disebut sebagai klaim utama dari Edwards di dalam bagian ini, maka pernyataan tersebut pastilah tertuang dalam kalimat ini:

Di atas semuanya, saya pikir sudahlah jelas dinyatakan, bahwa segala afeksi penuh anugerah yang sejati lahir dari pengaruhpengaruh yang khusus dan istimewa dari Roh Kudus, yang menghasilkan kesadaran atau sensasi di dalam jiwa orang-orang kudus, yang sepenuhnya berbeda dari apa yang bisa dialami oleh orang yang natural, bukan hanya dari segi derajat dan kondisi yang mengikutinya, tetapi sepenuhnya berbeda pada naturnya: sehingga seorang

\footnotetext{
${ }^{21}$ Lih. ibid., 114-116.

${ }^{22}$ Ibid., 197. Penekanan pada sumber aslinya.

${ }^{23}$ Lih. Biehl, Reading Religious Affections, 60-68.
}

manusia yang natural bukan hanya tidak bisa mengalami hal serupa, tetapi sematamata hanya akan mengalami hal lain yang betul-betul berbeda, dan betul-betul tidak setara [dengan yang dialami oleh manusia yang spiritual]; dan bahwa kekuatan manusia atau iblis tidak mampu untuk menghasilkan natur yang mirip ataupun serupa [dengan yang dialami oleh manusia yang spiritual $].{ }^{24}$

Dua hal yang patut diperhatikan dari kalimat di atas. Pertama, Edwards menyatakan bahwa semua afeksi yang penuh anugerah "lahir dari pengaruh-pengaruh yang khusus dan istimewa dari Roh Kudus.” Hal ini dimungkinkan oleh karena, di dalam ungkapan McDermott, "Roh Allah yang tinggal secara permanen." 25 Edwards menegaskan bahwa kenyataan inilah-yaitu Roh Allah yang tinggal secara permanen-yang membedakan orang yang spiritual dan yang natural. Dia menuliskan, "Roh Allah diberikan kepada orang-orang kudus untuk tinggal di dalam diri mereka, sebagai tempat tinggalnya untuk seterusnya." ${ }^{26}$ Dia melanjutkan, "Alkitab menggambarkan Roh Kudus, bukan sekadar bergerak dan sesekali memengaruhi orang-orang kudus, tetapi tinggal di dalam diri mereka sebagai bait-Nya, rumah kepunyaan-Nya, dan tempat tinggalNya untuk selamanya (1Kor. 3:16; 2Kor. 6:16; Yoh. 14:16-17)."27 Roh yang sama, menurut Edwards, tinggal di dalam diri orang-orang kudus untuk dua tujuan: (1) menjadi "dasar atau sumber dari natur dan kehidupan yang baru," 28 dan; (2) "bertindak dan mengomunikasikan dirinya di dalam naturnya sendiri," yaitu di dalam "kekudusan." 29

Kedua, sehubungan dengan yang pertama, afeksi yang penuh anugerah tidak dapat diha-

${ }^{24}$ Edwards, Religious Affections, 210. Keterangan ditambahkan oleh penulis.

${ }^{25}$ McDermott, Seeing God, 88.

${ }^{26}$ Edwards, Religious Affections, 200.

${ }^{27}$ Ibid.

${ }^{28}$ Ibid.

${ }^{29}$ Ibid., 201. 
silkan oleh kekuatan manusia. Edwards berpendapat bahwa,

... pengaruh-pengaruh yang penuh anugerah dengan orang-orang kudus sebagai subyeknya, dan akibat-akibat yang dihasilkan Roh Allah yang mereka alami, adalah sesuatu yang melampaui yang alami, sama sekali berbeda dari apa yang bisa seseorang temukan di dalam dirinya secara alami, atau dari mengamalkan prinsip-prinsip yang alami; dan tidak ada upaya untuk menyempurnakan kualifikasi-kualifikasi atau prinsip-prinsip yang alami, tidak ada upaya untuk meningkatkan atau meninggikan derajatnya, dan tidak ada satu pun upaya untuk menciptakannya, yang akan membawa seseorang mengalaminya; sebab pengalaman tesebut bukan hanya berbeda dari apa yang alami, dan dari semua yang bisa dialami oleh manusia natural, dari segi derajat dan kondisi yang mengikutinya; tetapi juga di dalam jenisnya; dan pengalaman tersebut jauh lebih agung dari apa yang alami. ${ }^{30}$

Dari penjelasan di atas, jelaslah bahwa, bagi Edwards, kerohanian yang sejati atau afeksi yang penuh anugerah tidak akan bisa dialami oleh manusia melalui kekuatannya sendiri, apalagi untuk menghasilkannya.

Berdasarkan pemaparan di atas, kita dapat melihat bahwa Edwards telah dengan sengaja memulai diskusinya tentang afeksi yang penuh anugerah, dengan meletakkan dasar yang vital bagi penelaahan selanjutnya. Ia menekankan bahwa tanpa Roh Kudus sebagai sumber, yang tinggal di dalam diri seseorang, maka tidak mungkin ada yang namanya kerohanian yang sejati. Dalam hal ini, Edwards membuat keutamaan karya Roh Kudus di dalam area spiritualitas menjadi lebih menonjol.

Paparan Edwards mengenai keutamaan karya Roh Kudus di dalam membentuk kerohanian yang sejati mengingatkan kita bahwa ibadah yang sejati juga tidak akan pernah ada tanpa pekerjaan Roh yang sama di dalamnya. Namun sayangnya, sejak permulaan sejarah

${ }^{30}$ Ibid., 205. gereja, "Perkembangan menuju pemahaman yang utuh terhadap doktrin Allah Tritunggal cenderung lebih lambat ketika berbicara tentang pribadi ketiga, daripada pribadi kedua."31 Meski ketertarikan terhadap doktrin Roh Kudus meningkat belakangan ini, "studi tentang ibadah sebagai wadah yang di dalamnya Roh Kudus hadir dan berkarya, pada dasarnya masih relatif marginal." 32

Mengesampingkan Roh Kudus di dalam ibadah komunal akan menghasilkan konsekuensi yang tidak kecil. Pertama, sehubungan dengan pemahaman kita tentang Allah yang kepada-Nya kita beribadah. Pada intinya, kekristenan percaya kepada Allah Tritunggal. Iman kepada Allah Tritunggal inilah yang membuat ibadah Kristen menjadi unik. Chan dengan tepat menuliskan bahwa, "Di dalam Allah yang menyatakan diri-Nya sebagai Bapa, Anak, dan Roh Kudus inilah yang menjadikan ibadah Kristen berbeda dari ibadahibadah agama lain, bahkan dari kepercayaan orang Yahudi yang sebenarnya adalah akar dari kekristenan." ${ }^{33}$ Lester Ruth menambahkan, "Menyembah Allah Tritunggal-lah yang menjadikan ibadah ortodoks." 34 Maka, tidak memberikan tempat yang seharusnya bagi Roh Kudus-bersama-sama dengan Bapa dan Anak-di dalam ibadah komunal, kita bisa terjebak ke dalam sebuah ibadah yang tidak ortodoks lagi.

Kedua, yaitu yang lebih penting, sehubungan dengan apa yang kita lakukan di dalam iba-

\footnotetext{
${ }^{31}$ Geoffrey Wainwright, Doxology: The Praise of God in Worship, Doctrine, and Life (New York: Oxford University Press, 1980), 87.

${ }^{32}$ Teresa Berger dan Bryan D. Spinks, "Introduction" dalam The Spirit in Worship-Worship in the Spirit, ed. Teresa Berger dan Bryan D. Spinks (Collegeville: Liturgical Press, 2009), xv. Lih. juga Simon Chan, "The Holy Spirit as the Fulfillment of the Liturgy," Liturgy 30, no. 1 (January-March 2015): 33.

${ }^{33}$ Simon Chan, Liturgical Theology: The Church as Worshipping Community (Downers Grove: InterVarsity, 2006), 58.

${ }^{34}$ Lester Ruth, "How Great is Our God: The Trinity in Contemporary Christian Worship Music," dalam The Message in the Music: Studying Contemporary Praise \& Worship, eds. Robert Woods dan Brian Walrath (Nashville: Abingdon, 2007), 30.
} 
dah komunal. Yang penulis maksudkan di sini adalah paradigma kita terhadap segala tindakan beribadah (liturgical acts) yang kita jalankan di dalam ibadah Minggu. Hal ini penting sebab kebanyakan diskusi dan perdebatan mengenai ibadah cenderung berkutat kepada apa yang semestinya kita lakukan di dalam ibadah komunal. Meski hal ini tidaklah salah, fokus terhadap "apa yang semestinya kita lakukan" dapat menjebak kita untuk menganggap bahwa di dalam ibadah komunal, apa yang kita lakukan, tindakan kita, itulah yang terpenting. Ketika hal ini terjadi-dan sering kali tanpa disadari, ini berarti kita telah dijangkiti oleh penyakit yang disebut "ibadah yang legalistik," bahwa ibadah adalah melulu tentang apa yang kita lakukan.

Contohnya, kita gampang sekali tergoda untuk menilai "keberhasilan" ibadah kita dari kesan yang dialami jemaat. Jika melalui sebuah ibadah komunal jemaat merasa terpuaskan, entah secara afektif atau kognitif, maka kita dengan mudah sekali menyimpulkan bahwa mereka telah mengalami ibadah yang sejati. Akibatnya, kita cenderung menganggap bahwa apa yang kita telah lakukan, entah sebagai perancang atau pelayan ibadah, itulah yang membuat seseorang bisa mengalami ibadah yang autentik. Jika jemaat tidak berkesan, maka kita merasa: "Oh, mungkin lagunya kurang bagus," atau, "Jangan-jangan karena si A main pianonya kurang piawai?" Tentu saja pemikiran-pemikiran ini tidak sepenuhnya salah. Tetapi menjadi salah ketika kita menganggap bahwa hal-hal inilah yang menjadi faktor penentu utama autentik atau tidaknya sebuah ibadah komunal. Maka, tanpa terus-menerus menyadari dan mengakui peran Roh Kudus di dalam ibadah komunal, kita akan dengan mudah mereduksi ibadah sebagai sesuatu yang kita lakukan untuk Tuhan daripada sebagai sebuah respons terhadap panggilan anugerah yang Tuhan berikan untuk berjumpa dengan-Nya.

Dalam hal ini, $R A$ dapat menjadi sejenis "penawar" bagi kecenderungan kita yang memandang dan mempraktikkan ibadah secara legalistik. $R A$ mengingatkan kita bahwa ibadah yang sejati, sama seperti kerohanian yang sejati, tidak pernah dihasilkan oleh kekuatan manusia. Sebaliknya, itu adalah pekerjaan Roh Kudus, yang tinggal secara permanen di dalam diri seseorang yang spiritual, yang memampukan orang tersebut untuk berjumpa dengan Tuhan di dalam ibadah komunal. Jadi, ibadah yang sejati tidak pernah dimulai dengan memikirkan apa yang bisa kita lakukan, melainkan dengan mengakui bahwa kita tidak bisa melakukan apa pun tanpa anugerah Tuhan melalui Roh KudusNya.

\section{Religious Affections dan Ibadah yang Narsi- sistik: Tanda 2}

Setelah menonjolkan peran Roh Kudus di tanda pertama, di tanda kedua Edwards menuliskan bahwa, "Yang menjadi dasar obyektif yang mula-mula dari afeksi yang penuh anugerah, adalah keagungan yang sifatnya transenden dan natur keelokan dari hal-hal yang ilahi, sebagaimana yang ada pada dirinya sendiri; dan bukan karena terkait dengan diri kita, atau demi keuntungan pribadi." 35 Di bagian ini, dia menyatakan bahwa karena afeksi kasih adalah "sumber dari segala afeksi; dan secara khusus, bahwa kasih kristiani adalah sumber dari afeksi yang penuh anugerah," maka kerohanian sejati lahir terutama dari kecintaan kepada "keagungan dan kemuliaan Tuhan, dan Yesus Kristus, Firman Allah, karya-karya Tuhan, dan jalan-jalan Tuhan," dan bukan karena mencintai diri sendiri atau mencari kepentingan pribadi. ${ }^{36}$ Sederhananya, seseorang yang memiliki afeksi yang penuh anugerah, ialah orang yang pertamatama mencintai Tuhan karena diri-Nya sendiri, dan bukan karena berkat yang bisa diterima dari Tuhan.

Penting untuk dicatat dalam hal ini, bahwa Edwards tidak pernah bermaksud mengatakan bahwa kita harus menyangkal kepentingan pribadi, atau kita tidak pernah boleh mencintai diri sendiri. Dia juga tidak bermak-

\footnotetext{
${ }^{35}$ Edwards, Religious Affections, 240.

${ }^{36}$ Ibid.
} 
sud bahwa kita tidak boleh memupuk cinta kita kepada Tuhan di atas dasar berkat-berkat yang bisa Tuhan berikan untuk kita. Apa yang dia tegaskan adalah bahwa, "Seseorang haruslah pertama-tama mencintai Tuhan, atau membuat hatinya berpadu dengan Dia, sebelum dia menganggap berkat Tuhan sebagai miliknya, dan sebelum dia ingin mengalami kesenangan yang diakibatkan oleh memuliakan dan menikmati Tuhan." ${ }^{37}$ Baginya, "dasar pertama-tama dari cinta yang sejati kepada Tuhan adalah bahwa Tuhan di dalam diri-Nya sendiri begitu indah, atau layak untuk dicintai, atau merupakan keindahan yang tertinggi." 38 Allah di dalam natur-Nya, menurut Edwards, "teramat agung." Itulah sebabnya, Edwards bertanya-tanya: "Bagaimana seseorang bisa betul-betul mencintai Tuhan dengan benar, tanpa mencintai Dia karena keagunganNya?"39 Bagi mereka yang mencintai Tuhan karena apa yang bisa didapatkan dari Tuhan, Edwards dengan keras menyatakan bahwa,

... afeksi mereka dimulai dari sudut yang keliru; mereka mengindahkan Tuhan hanya sebatas ketika kebaikan-kebaikanNya menyentuh dan memenuhi minat mereka; dan [mereka] sama sekali tidak menghormati natur Allah yang mahamulia, yang adalah "yang baik" itu sendiri, dan merupakan sumber sejati dari segala yang baik, sumber mula-mula dari segala jenis keelokan, dan oleh karena itu merupakan dasar permulaan dari cinta yang sejati. ${ }^{40}$

Edwards melanjutkan argumennya dengan memberikan beberapa contoh yang bisa membuktikan bahwa bahkan ekspresi rasa terima kasih kepada Tuhan tidak selalu menunjukkan kerohanian yang sejati, sebab ekspresi tersebut bisa saja muncul dari kepentingan pribadi. Baginya, "hal yang alami sudah cukup untuk membangkitkan rasa terima kasih di dalam diri seseorang,"

\footnotetext{
${ }^{37}$ Ibid., 241.

${ }^{38}$ Ibid., 242.

${ }^{39}$ Ibid., 243.

${ }^{40}$ Ibid. Keterangan bukan pada sumber aslinya.

${ }^{41}$ Ibid.
}

dari sesuatu yang alami saja bisa berterima kasih kepada manusia lain; demikian halnya juga kepada Tuhan." 42 Cinta yang seperti ini, menurut Edwards, hanyalah muncul karena seseorang mendapati bahwa Tuhan mengasihi dia dan begitu baik kepadanya, dan bukan utamanya karena mereka mendapati bahwa Tuhan di dalam dirinya sendiri begitu indah.

Penjelasan Edwards mengingatkan kita akan satu hal yang senantiasa perlu kita refleksikan setiap kali kita memikirkan apa itu ibadah yang sejati, yaitu jawaban dari pertanyaan-pertanyaan ini: "Mengapa kita beribadah kepada Tuhan? Apakah kita beribadah kepada-Nya semata-mata karena Dia layak disembah? Ataukah, kita beribadah kepadaNya karena kita telah menerima apa yang kita mau dari Dia? Ketika Allah tidak lagi memberikan apa yang kita mau, masihkah kita beribadah kepada-Nya?" Di dalam risalahnya, Edwards telah menunjukkan beberapa contoh dari Alkitab, bahwa ada orang-orang yang begitu antusias memuji Tuhan, tetapi kemudian begitu gampang tidak lagi percaya kepada-Nya ${ }^{43}$ Faktanya, hal ini pun terjadi di dalam ibadah komunal hari ini. Kita sering melihat orang-orang memuji Tuhan dengan sangat bersemangat, tetapi ketika persoalan hidup melanda, mereka dengan mudah meragukan Tuhan. Itulah sebabnya Edwards mengingatkan kita, cinta sejati kepada Tuhan selalu dimulai dari mencintai Tuhan "apa adanya," bukan karena "ada apanya." Mencintai Tuhan demi diri sendiri sesungguhnya bukanlah cinta kepada Tuhan, tetapi cinta kepada diri, yang dalam istilah hari ini disebut "cinta yang narsisistik."

Belajar dari Edwards, kita melihat betapa pentingnya untuk melawan konsep-konsep narsisistik yang mewabah di dalam budaya hari ini, khususnya yang muncul di dalam ibadah komunal. Jika kita gagal, maka yang terjadi adalah munculnya pengertian ibadah yang keliru. Pertama, kita akan cenderung beranggapan bahwa yang paling penting dalam ibadah adalah semata-mata meng-

\footnotetext{
${ }^{42}$ Ibid., 244.
}

${ }^{43}$ Lih. ibid. 
ekspresikan apa yang kita rasakan tentang Tuhan. Kita memuji Tuhan karena kita telah menikmati berkat-Nya, dan itu membuat kita merasa senang dan ingin mengekspresikannya sewaktu ibadah. Padahal, ibadah yang sejati, sebagaimana yang dituliskan Chan, berbicara tentang "mengakui Tuhan sebagaimana adanya diri-Nya."44 Maka ibadah sejatinya adalah memuliakan Tuhan oleh karena kita telah terpikat dengan keagungan Tuhan. Ibadah, pertama-tama, bukanlah soal memuji Tuhan karena apa yang telah dia lakukan untuk kita-yaitu yang sesuai dengan minat kita, melainkan mengakui keindahan Tuhan yang telah menawan kita, dan yang membawa kita untuk meresponsnya dengan cara menyembah Dia.

Kedua, ibadah yang narsisistik membuat kita berpikir bahwa ibadah sesungguhnya adalah demi keuntungan kita, dan bukan demi kemuliaan Tuhan. ${ }^{45}$ Hari ini, bukan lagi merupakan rahasia jika banyak orang Kristen memilih gereja terutama karena apa yang mereka bisa dapatkan dari ibadahnya. Mereka yang ingin mendapatkan hiburan, akan memilih gereja dengan ibadah yang diiringi oleh tim musik profesional, atau piawai dalam menampilkan pertunjukan. Mereka yang ingin terpenuhi secara intelektual, cenderung memilih gereja yang memiliki pengkhotbah ulung, bahkan jika perlu, yang bergelar Profesor atau Dok-

\footnotetext{
${ }^{44}$ Chan, Liturgical Theology, 52-53.

${ }^{45}$ Konsep ini utamanya diusulkan oleh Jack Hayford, pencipta lagu terkenal yang berjudul "Mulia (Majesty)," di dalam bukunya Worship His Majesty (Waco: Word, 1987) 41-50. Di dalam tulisannya yang lain, Hayford bahkan menegaskan bahwa konsep ini adalah semacam "teologi ibadah" yang dianutnya. Menurutnya, "Fokus utama Tuhan dengan memberikan akses kepada kita untuk menyembah Dia adalah untuk menyediakan sebuah exposure and experience yang memang dikhususkan untuk kepentingan kita, bukan untuk Tuhan. ..." ("Getting to the Heart of Worship: Reassessing God's Expectations of Our Worship," Jack Hayford Ministry, diakses 10 Januari 2016. http://www.jackhayford.org/teaching/articles/ getting-to-the-heart-of-worship-reassessing-gods-expectations-of-our-worship/). Tampaknya Hayford tidak bisa membedakan mana yang merupakan tujuan beribadah, mana yang merupakan dampak yang dihasilkan ketika seseorang beribadah dengan sungguh. Ibadah pasti membawa keuntungan bagi kita, tetapi itu tidak pernah menjadi tujuan dari ibadah.
}

tor. Dengan kondisi seperti ini, gereja-gereja berlomba untuk menyajikan ibadah yang dapat memenuhi harapan atau selera jemaat. Tetapi pilihan ini harus dibayar dengan harga yang mahal, yaitu bergesernya makna ibadah komunal. Marva Dawn dengan tepat menyatakan bahwa, "Akibat terburuk dari mengubah ibadah menjadi sesuatu yang dikendalikan oleh selera adalah, ketika kita melakukannya, kita telah menutup mata kita terhadap sebuah kebenaran bahwa Tuhanlah yang seharusnya disembah, bukan diri kita." 46

$R A$ sekali lagi dapat menolong kita untuk ingat bahwa meski ibadah yang sejati akan menghasilkan manfaat, ibadah tidak pernah bertujuan untuk memenuhi keinginan kita. Edwards menolong kita untuk terus bertanya kepada diri sendiri sewaktu kita tidak ibadah, apakah yang kita susun menolong jemaat untuk mencintai Tuhan dan menyembah Dia sebagaimana adanya diri-Nya. Edwards juga mendorong kita untuk terus mengevaluasi diri setiap kali kita berkumpul untuk beribadah, apakah kita datang dan menyembah Tuhan karena keagungan-Nya. Ibadah yang sejati semestinya membentuk kita untuk lebih melihat kemuliaan Tuhan dan terpikat oleh apa yang kita lihat tersebut.

\section{Religious Affections dan Ibadah yang Tera- peutik: Tanda 3}

Jika di tanda kedua Edwards menekankan tentang mencintai Tuhan karena keagunganNya, di tanda ketiga dia membahas lebih dalam tentang apa yang dia maksudkan sebagai "keagungan" Tuhan. Dia menyatakan: "Afeksi yang betul-betul kudus, utamanya ditemukan di dalam kecintaan terhadap keagungan moral dari hal-hal yang ilahi. Atau (dengan kata lain), cinta terhadap hal-hal yang ilahi oleh karena keindahan dan keelokan dari keagungan moralnya, adalah permulaan dan sumber dari segala afeksi yang kudus." ${ }^{47}$ Di sini kita melihat bahwa kea-

\footnotetext{
${ }^{46}$ Marva J. Down, A Royal Waste of Time: The Splendor of Worshiping God and Being Church for the World (Grand Rapids: Eerdmans, 1999), 192.
}

${ }^{47}$ Edwards, Religious Affections, 253-254. 
gungan yang dimaksud oleh Edwards adalah yang bersifat moral.

Sebelum menjelaskan apa itu "keagungan moral dari Tuhan," Edwards terlebih dahulu mengklarifikasi apa yang dia maksud dengan istilah "moral." Dalam hal ini, Edwards memanfaatkan pembedaan yang sudah ada sebelumnya, yaitu antara kebaikan dan kejahatan yang sifatnya moral, dengan yang sifatnya natural. ${ }^{48}$ Kejahatan moral (moral evil) adalah "kejahatan dosa, yang bertentangan dengan apa yang benar atau seharusnya," sementara kejahatan natural (natural evil) adalah sesuatu yang "semata-mata bertentangan dengan alam." ${ }^{49}$ Di pihak lain, kebaikan moral (moral good) dipahami sebagai sesuatu yang "bertentangan dengan dosa, atau kebaikan di dalam diri makhluk yang memiliki kehendak dan pilihan, yang melaluinya, mereka, sebagai agen-agen yang sukarela, hidup dan bertindak sebagaimana mestinya." Sebaliknya, kebaikan natural adalah sesuatu yang "sama sekali tidak terkait dengan kekudusan atau kebaikan... dan sama sekali tidak berhubungan dengan aturan atau ukuran mengenai apa yang benar dan salah." 50

Berdasarkan klarifikasi tersebut, Edwards kemudian menjelaskan apa yang dia maksud sebagai "keagungan moral dari Tuhan," yaitu "segala atribut yang diimplementasikan oleh Tuhan sebagai agen moral . . . seperti ke-benar-annya (righteousness), kebenaran (truth), kesetiaan, dan kebaikan.” Menurut Edwards, atribut-atribut tersebut dapat diwakili dengan satu kata, yaitu "kekudusan (holiness)." 51 Sebaliknya, keagungan natural Tuhan mengacu kepada atribut-atribut yang menjelaskan kebesaran Tuhan, seperti kekuasaan-Nya, kemahatahuan-Nya, kekekalanNya, kemahahadiran-Nya, dan kemuliaanNya yang begitu mengagumkan. ${ }^{52}$ Singkatnya, keagungan moral Tuhan mengacu pada

\footnotetext{
${ }^{48}$ Ibid., 254.

${ }^{49}$ Ibid.

${ }^{50}$ Ibid.

${ }^{51}$ Ibid., 255.

${ }^{52}$ Ibid.
}

kekudusan-Nya, sedangkan keagungan natural Tuhan mengacu pada kebesaran-Nya.

Dari penjelasan di atas, jelaslah bahwa apa yang Edwards maksudkan adalah, "Orangorang yang kudus, di dalam mengamalkan afeksi yang kudus, mencintai hal-hal yang ilahi utamanya karena kekudusannya: mereka mencintai Tuhan, pertama-tama, karena keindahan dari kekudusan-Nya atau kesempurnaan moral-Nya, begitu menawan di dalam diri-Nya sendiri." 53 Bagi Edwards, "Mencintai Tuhan karena keindahan atribut-atribut moral-Nya, akan membuat seseorang bersuka di dalam Tuhan oleh karena atribut-atribut lainnya juga." Tetapi kemudian dia menambahkan, "Cinta yang sejati kepada Tuhan haruslah dimulai dengan kesukaan terhadap kekudusan-Nya, dan bukan dengan atributatribut lainnya." Sebagai tambahan, ia juga menghubungkan deskripsinya di bagian ini dengan dua tanda sebelumnya. Seseorang yang spiritual mencintai kekudusan Tuhan oleh karena karya supranatural dari Roh Kudus yang tinggal di dalam diri orang tersebut. ${ }^{54}$ Karya supranatural Roh Kuduslah yang kemudian menuntun afeksi seseorang untuk mencintai Tuhan bukan karena Tuhan memenuhi selera pribadinya, melainkan karena siapa Tuhan itu sendiri, yaitu Tuhan yang kudus. $^{55}$

Di dalam analisis mereka khususnya terhadap remaja-remaja di Amerika, Smith dan Denton menyimpulkan bahwa, "fakta yang dominan tentang agama di antara remajaremaja hari ini di Amerika adalah sesuatu yang kita bisa sebut sebagai 'Moralistic Thera-

\footnotetext{
${ }^{53}$ Ibid., 256.

${ }^{54}$ Lih. ibid., 259.

${ }^{55}$ Lih. ibid., 262-263.
} 
peutic Deism (MTD)'"56 “Tuhan" yang dipahami oleh konsep ini, oleh Smith dan Denton, dideskripsikan sebagai ibarat seseorang yang "selalu standby di telepon, membereskan semua masalah yang muncul, secara profesional menolong umat-Nya merasa lebih baik, dan tidak akan terlibat terlalu dalam di dalam prosesnya." ${ }^{57}$ Menariknya, Smith mencatat bahwa "agama" jenis ini tidak berdiri sendiri. Dia seolah, tanpa disadari, menempel seperti parasit kepada agama-agama yang sudah ada, termasuk kekristenan. ${ }^{58}$ Ini berarti orang Kristen dan juga ibadah Kristen tidaklah kebal terhadap pengaruh konsep ini.

Aspek yang paling menonjol dari MTD, yang relevan terhadap pembahasan kita adalah aspek terapeutik. Sebagaimana yang telah dijabarkan sebelumnya, di dalam ibadah hari ini jemaat lebih suka untuk mendengar halhal yang menyatakan kebesaran kasih Tuhan dan betapa baiknya Dia kepada kita. Gerejagereja kemudian meresponsnya dengan mempresentasikan figur Tuhan yang lebih bersahabat. Misalnya, lebih banyak khotbah tentang meyakinkan jemaat bahwa mereka sangat dikasihi oleh Tuhan. Contoh lain, puji-pujian yang dinyanyikan didominasi dengan yang berbicara tentang janji bahwa Tuhan akan selalu bersama kita, melindungi dan membuat kita tenteram. Beberapa gereja bahkan menghilangkan elemen pengakuan dosa dari tata ibadah mereka karena elemen ini dianggap tidak membuat jemaat merasa lebih nyaman. Di dalam ibadah yang terapeutik semacam ini, segala hal tentang kekudusan Tuhan

\footnotetext{
${ }^{56}$ Christian Smith dan Melinda Lundquist Denton, “On 'Moralistic Therapeutic Deisme' as U.S. Teenagers' Actual, Tacit, De Facto Religious Faith," The Princeton Lectures on Youth, Church, and Culture (2005): 46, diakses 6 November 2015, https://www.ptsem.edu/uploadedFiles/School_of_Christian_Vocation_and_Mission/ Institute_for_Youth_Ministry/Princeton_Lectures/SmithMoralistic.pdf. Untuk diskusi yang lebih mendalam tentang topik ini, lih. Christian Smith dan Melinda Lundquist Denton, Soul Searching: The Religious and Spiritual Lives of American Teenagers (New York: Oxford University Press, 2005).
}

${ }^{57}$ Ibid., 50.

${ }^{58}$ Ibid., 51. akan diminimalkan sebab jemaat tidak terlalu nyaman dengan figur Allah yang kudus.

Di sinilah argumen Edwards juga bermanfaat dalam area ibadah. Idenya tentang kekudusan Allah mengingatkan kita bahwa, pertama, di dalam ibadah komunal, kita datang untuk berjumpa dengan Allah yang kudus. Contoh yang paling jelas dari perjumpaan ini adalah pada waktu Allah menyatakan diriNya kepada Yesaya (Yes. 6). Di dalam penglihatannya, Yesaya melihat serafim memproklamasikan pribadi Tuhan yang menyatakan diri-Nya, dengan berseru: "Kudus, kudus, kuduslah TUHAN semesta alam, seluruh bumi penuh kemuliaan-Nya." Implikasinya jelas, bahwa ketika kita memahami ibadah sebagai pertemuan dengan Tuhan, maka mustahil ada ibadah yang sejati tanpa perjumpaan dengan Allah yang kudus. Dengan kata lain, tidak akan ada ibadah yang sejati tanpa disertai dengan kerinduan untuk mendekat kepada Allah yang kudus, yang memanggil kita untuk menyembah Dia.

Kedua, menyembah Tuhan di dalam kekudusan-Nya juga merupakan testing ground bagi kita, apakah kita sedang menyembah Tuhan atau diri sendiri. Apakah kita menyembah Tuhan supaya merasa lebih baik atau lebih nyaman, atau supaya kita makin tertawan oleh indahnya kekudusan Tuhan? Senada dengan Edwards, David Wells menuliskan bahwa, "Kekudusan adalah definisi paling fundamental tentang karakter Tuhan." 59 Maka, Wells melanjutkan, "sebuah visi tentang kekudusan yang demikian seharusnya menginspirasi umat-Nya dan membangkitkan ibadah mereka, menjaga karakter mereka, membakar gairah mereka untuk melakukan kehendak-Nya dan menyebut nama-Nya di dalam doa-doa mereka." ${ }^{60}$ Kita beribadah kepada Tuhan bukan karena aktivitas itu membuat kita merasa lebih baik, melainkan karena kita tidak mungkin melakukan yang lain selain bersimpuh di hadapan Allah yang kudus.

\footnotetext{
${ }^{59}$ David F. Wells, God in the Wasteland: The Reality of Truth in a World of Fading Dreams (Grand Rapids: Eerdmans, 1994), 136.

${ }^{60}$ Ibid.
} 
Penekanan Edwards tentang keagungan moral Tuhan adalah penawar yang tepat untuk pemahaman tentang ibadah yang keliru, yaitu ibadah terapeutik. Penekanan ini menolong kita untuk melawan kecenderungan kita untuk menyembah Allah yang kita ciptakan sendiri di kepala kita, yaitu Allah yang tugas utamanya adalah untuk membuat kita merasa lebih baik. Penekanan ini juga memanggil kita untuk berpikir lebih dalam mengenai bagaimana cara kita mengakui dan mengartikulasikan kekudusan Tuhan di dalam liturgi ibadah, agar ibadah kita bisa menolong jemaat untuk menyembah Tuhan dengan tepat.

\section{Kesimpulan dan Saran}

Artikel ini telah mencoba untuk menunjukkan bahwa $R A$, khususnya tiga tanda dari afeksi yang penuh anugerah, dapat bermanfaat di dalam area ibadah komunal. Ditulis untuk menjawab problematika mengenai natur dari agama yang sejati, $R A$ tidak hanya penuh dengan hikmat yang bernilai, tetapi juga menolong kita untuk menetralkan beberapa ide yang keliru dan berbahaya tentang ibadah, yaitu ibadah yang legalistik-yang terpenting dalam ibadah adalah apa yang kita lakukan, ibadah yang narsisistik - yang terpenting adalah bagaimana ibadah bisa menjawab kebutuhan kita, dan ibadah yang terapeutik-yang terpenting adalah bagaimana ibadah bisa membuat kita merasa lebih baik. Sumbangsih Edwards untuk melawan tiga kekeliruan ini adalah pertama, menekankan keutamaan karya Roh Kudus di dalam ibadah; kedua, menekankan pentingnya menyembah Tuhan sebagaimana diri-Nya di dalam ibadah, dan; ketiga, menekankan pentingnya menyembah Allah di dalam kekudusan-Nya di dalam ibadah. Kesimpulannya, ibadah yang sejati bersumber dari karya supranatural yang dikerjakan Roh Kudus, yang kemudian menawan kita untuk mencintai Tuhan sebagaimana Dia adanya dan menyembah Dia di dalam kekudusan-Nya.

Ada beberapa cara praktis untuk mengaplikasikan sumbangsih Edwards di dalam ibadah komunal. Pertama-tama, terkait dengan mengakui keutamaan karya Roh Kudus, kita dapat menumbuhkan kesadaran ini melalui membiasakan diri bersaat teduh sebelum ibadah dimulai. Tentu saja praktik ini bukanlah hal yang baru bagi kebanyakan gereja. Sayangnya, momen bersaat teduh sering kali tidak dimanfaatkan dengan maksimal. Misalnya, waktu yang diberikan terlalu singkat. Bahkan hanya untuk mengatur nafas dan menenangkan pikiran saja tidak cukup, apalagi untuk menata hati untuk siap menghadap Tuhan. Bagi mereka yang melayani, tidak jarang momen ini terlewatkan begitu saja karena terlalu sibuk mempersiapkan bagian selanjutnya. Maka pertanyaan teologis dan praktis yang patut diajukan adalah, "Atas dasar apakah kita datang menyembah Tuhan? Apakah semata-mata karena kekuatan determinasi diri dan pilihan pribadi yang kita buat?"

Saat teduh sebelum ibadah mulai sejatinya dapat menjadi momen yang sangat formatif bagi pemahaman dan praktik ibadah kita. Di momen ini, kita belajar untuk menyerahkan roh kita kepada Tuhan, dan memohon agar Roh Tuhan sendiri yang mengendalikan kita ketika kita menjumpai Tuhan. ${ }^{61}$ Melalui praktik seperti ini, kita melatih diri untuk terus mengakui kebergantungan kita kepada karya Roh Kudus, bahwa kita tidak bisa melakukan apa-apa di dalam ibadah tanpa Roh Kudus yang bekerja di dalam diri kita. Di saat yang sama, kita sebenarnya sedang mereformasi kecenderungan kita untuk menganggap ibadah sebagai sesuatu yang kita lakukan untuk Tuhan, bukan apa yang Tuhan kerjakan di dalam penyerahan diri kita kepada-Nya. Ibadah komunal yang sejati perlu menolong jemaat untuk bergantung kepada karya Roh Kudus bahkan sebelum liturgi ibadah itu dimulai.

Selanjutnya, sehubungan dengan menyembah Tuhan sebagaimana diri-Nya, kita dapat mengimplementasikannya dengan

${ }^{61}$ Ide ini penulis dapatkan dari Pdt. Hendra G. Mulia, sewaktu beliau menjadi pembicara di National Worship Convention yang diselenggarakan oleh Sinode Gereja Kristus Yesus, 30 April-2 Mei 2015. 
cara menyanyikan lebih banyak pujian yang menonjolkan pribadi Tuhan dan karya-Nya, daripada pujian yang berfokus pada apa yang kita pikirkan tentang Tuhan. Perlu disadari bahwa puji-pujian yang kita nyanyikan dalam ibadah membawa pengaruh yang signifikan terhadap spiritualitas kita, khususnya dalam membentuk pemahaman kita tentang Tuhan, dan yang lebih penting, dalam membentuk respons kita kepada Tuhan. Pujian yang terus mengatakan kepada kita bahwa Tuhan sangat baik karena Dia memberikan apa yang kita minta tidaklah menolong, selain hanya "memberi makan" selera diri sendiri daripada menyembah Tuhan.

Sayangnya, banyak gereja tidak terlalu menginvestasikan waktu dan perhatian untuk hal ini. Pilihan lagu-lagu yang dinyanyikan sering kali hanya didasarkan pada selera musik tertentu atau mana yang paling bisa mengekspresikan emosi. Dalam hal ini, mereka yang bertugas merancang ibadah juga harus memikirkan aspek formatif dari puji-pujian yang dipilih. Tujuan akhir yang harus dikejar adalah bagaimana melalui puji-pujian yang dinyanyikan, jemaat dapat mengartikulasikan secara tepat penyembahannya kepada Tuhan. Ibadah komunal yang sejati harus menolong jemaat untuk melihat Tuhan sebagaimana adanya diri-Nya, dan bagaimana kita harus merespons-Nya dengan tepat.

Terakhir, berkenaan dengan kekudusan Tuhan, sudah merupakan keharusan untuk mempertahankan elemen pengakuan dosa dan janji pengampunan dosa di dalam tata ibadah. Elemen ini mungkin masih menjadi sarana terbaik di sepanjang ibadah, yang dengan sangat kuat mengingatkan diri kita bahwa Allah yang kepada-Nya kita menyembah adalah Allah yang kudus, dan sudah sepatutnya kita menghormati kekudusan-Nya. Dengan mengaku dosa, kita akan menumbuhkan kepekaan yang lebih tinggi mengenai kekudusan Tuhan, tidak hanya di dalam ibadah komunal saja, tetapi juga bahkan di dalam kehidupan sehari-hari kita.

Untuk membuat aspek ini formatif di dalam ibadah komunal, maka memberikan waktu yang cukup bagi jemaat untuk berdoa secara pribadi sangatlah signifikan. Dalam pengalaman penulis, acapkali iringan musik atau nyanyian akan lebih menganggu daripada membantu. Memberikan kesempatan bagi jemaat untuk menghadap Tuhan dalam keheningan merupakan sarana bagi Roh Kudus bekerja untuk menyadarkan kita akan kekudusan Tuhan dan kelemahan kita. Namun, di saat yang sama, jemaat perlu mendengar janji pengampunan dosa dari Tuhan sendiri. Momen ini dapat menjadi sarana bagi Roh Kudus berkarya untuk mengalami indahnya kekudusan Tuhan yang membungkus kelemahan kita, sekaligus menguatkan tekad kita untuk hidup dalam kekudusan. Ibadah komunal yang sejati perlu terus-menerus menolong jemaat untuk mencintai Tuhan yang kudus dan kehidupan yang kudus. 


\section{Daftar Kepustakaan}

Berger, Teresa, dan Bryan D. Spinks. "Introduction." Dalam The Spirit in Worship-Worship in the Spirit, diedit oleh Teresa Berger dan Bryan D. Spinks, xi-xxv. Collegeville: Liturgical, 2009.

Biehl, Craig. Reading Religious Affections: A Study Guide to Jonathan Edwards' Classic on the Nature of True Christianity. Birmingham: Solid Ground Christian Books, 2012.

Byars, Ronald P. The Future of Protestant Worship: Beyond the Worship Wars. Louisville: Westminster John Knox, 2002.

Chan, Simon. "The Holy Spirit as the Fulfillment of the Liturgy." Liturgy 30, no. 1 (JanuaryMarch 2015): 33-41.

\section{Varsity, 2006.}

Cherry, Conrad. The Theology of Jonathan Edwards: A Reappraisal. Indianapolis: Indiana University Press, 1990.

Dawn, Marva J. A Royal Waste of Time: The Splendor of Worshiping God and Being Church for the World. Grand Rapids: Eerdmans, 1999.

Dyrness, William. A Primer of Christian Worship: Where We've Been, Where We Are, Where We Can Go. Grand Rapids: Eerdmans, 2009.

Edwards, Jonathan. Religious Affections in The Works of Jonathan Edwards, vol. 2, diedit oleh John E. Smith. New Haven: Yale University Press, 1959.

Hayford, Jack. "Getting to the Heart of Worship: Reassessing God's Expectations of Our Worship.” Jack Hayford Ministry. Accessed November 6, 2015. http://www.jackhayford.org/teaching/articles/getting-to-the-heart-of-worship-reassessing-gods-expectations-of-our-worship/. . Worship His Majesty. Waco: Word, 1987.

Hotz, Kendra G., dan Matthew T. Mathews. Shaping the Christian Life: Worship and the Religious Affections. Louisville: Westminster John Knox, 2006.

Long, Thomas G. Beyond the Worship Wars: Building Vital and Faitful Worship. Bethesda: The Alban Institute, 2001.

Marsden, George. Jonathan Edwards: A Life. New Haven: Yale University Press, 2003.

McDermott, Gerald R. Seeing God: Twelve Reliable Signs of True Spirituality. Downers Grove: InterVarsity, 1995.

Nichols, Stephen J. Jonathan Edwards: A Guided Tour of His Life and Thought. Phillipsburg: P\&R, 2001.

Rivera, Ted. Jonathan Edwards on Worship: Public and Private Devotion to God. Eugene: Pickwick, 2010.

Ruth, Lester. "How Great is Our God: The Trinity in Contemporary Christian Worship Music." Dalam The Message in the Music: Studying Contemporary Praise \& Worship, diedit oleh Robert Woods dan Brian Walrath, 29-42. Nashville: Abingdon, 2007.

Smart, Robert Davis. Jonathan Edwards's Apologetics for the Great Awakening. Grand Rapids: Reformation Heritage, 2011. 
Smith, Christian, dan Melinda Lundquist Denton. Soul Searching: The Religious and Spiritual Lives of American Teenagers. New York: Oxford University Press, 2005.

. 'On 'Moralistic Therapeutic Deism' as U.S. Teenagers' Actual, Tacit, De Facto Religious Faith," The Princeton Lectures on Youth, Church, and Culture (2005): 46. Accessed November 6, 2015. https://www.ptsem.edu/uploadedFiles/School_of_Christian_Vocation_ and_Mission/Institute_for_Youth_Ministry/Princeton_Lectures/Smith-Moralistic.pdf.

Smith, John E. Editor's Introduction to Religious Affections, by Jonathan Edwards, 1-83. New Haven: Yale University Press, 1959.

Storms, Sam. Signs of the Spirit: An Interpretation of Jonathan Edwards' "Religious Affections." Wheaton: Crossway, 2007.

The Robert Webber Institute for Worship Studies. "IWS Bibliography January 2015.” Accessed October 22, 2015. https://iws.edu/2014/12/iws-bibliography-jan-2015/.

Towns, Elmer L. Putting an End to Worship Wars. Nashville: Broadman \& Holman, 1997.

Wainwright, Geoffrey. Doxology: The Praise of God in Worship, Doctrine, and Life. New York: Oxford University Press, 1980.

Wells, David F. God in the Wasteland: The Reality of Truth in a World of Fading Dreams. Grand Rapids: Eerdmans, 1994.

White, Susan J. Spirit of Worship: The Liturgical Tradition. Maryknoll: Orbis, 1999. 